\title{
New Molecular Targeted Therapy and Redifferentiation Therapy for Radioiodine-Refractory Advanced Papillary Thyroid Carcinoma: Literature Review
}

\author{
Kai-Pun Wong and Brian Hung-Hin Lang \\ Division of Endocrine Surgery, Department of Surgery, The University of Hong Kong, Queen Mary Hospital, \\ Pokfulam Road, Hong Kong, Hong Kong \\ Correspondence should be addressed to Brian Hung-Hin Lang, blang@hku.hk
}

Received 1 October 2012; Accepted 3 December 2012

Academic Editor: Katsuhiro Tanaka

Copyright ( $) 2012$ K.-P. Wong and B. H.-H. Lang. This is an open access article distributed under the Creative Commons Attribution License, which permits unrestricted use, distribution, and reproduction in any medium, provided the original work is properly cited.

\begin{abstract}
Although the majority of papillary thyroid carcinoma could be successfully managed by complete surgical resection alone or resection followed by radioiodine ablation, a small proportion of patients may develop radioiodine-refractory progressive disease which is not amenable to surgery, local ablative treatment or other treatment modalities. The use of FDG-PET/CT scan for persistent/recurrent disease has improved the accuracy of restaging as well as cancer prognostication. Given that patients with RAIrefractory disease tend to do significantly worse than those with radioiodine-avid or non-progressive disease, an increasing number of phase I and II studies have been conducted to evaluate the efficacy of new molecular targeted drugs such as the tyrosine kinase inhibitors and redifferentiation drugs. The overall response rate of these drugs ranged between $0-53 \%$, depending on whether the patients had been previously treated with these drugs, performance status and extent of disease. However, drug toxicity remains a major concern in administration of target therapies. Nevertheless, there are also ongoing phase III studies evaluating the efficacy of these new drugs. The aim of the review was to summarize and discuss the results of these targeted drugs and redifferentiation agents for patients with progressive, radioiodine-refractory papillary thyroid carcinoma.
\end{abstract}

\section{Introduction}

Papillary thyroid carcinoma (PTC) is the most common type of differentiated thyroid carcinoma (DTC) and its ageadjusted incidence has doubled in the last 25 years [1]. Despite its relatively good prognosis with a 10 -year cancerspecific survival above 90\%, locoregional recurrences and distant metastasis do occur not infrequently [2]. Of the 5$20 \%$ patients who may develop locoregional recurrences, approximately two-thirds of these recurrences involved the cervical lymph nodes. On the other hand, up to $10-15 \%$ patients would either present with distant metastasis at diagnosis or develop distant metastasis some time after initial treatment [3]. It is not uncommon to encounter patients with initial persistent locoregional recurrence who also later develop distant metastasis. Perhaps, this is a sign of disease progression. Since most patients would have had a total thyroidectomy and radioiodine (RAI) ablation as their initial therapy, disease monitoring or surveillance often relies on regular measurement of thyroglobulin ( $\mathrm{Tg}$ ) and high resolution neck ultrasound (USG) [4]. FDG-PET/CT scan is now often used as a staging tool in patients with suspected disease recurrence.

In terms of treating locoregional recurrence, a formal selective neck dissection for lymph node recurrence is usually preferred but at times when certain compartments has been previously dissected, a focused neck dissection or completion compartmental neck dissection might be preferred [2]. However, despite the best surgical effort, only approximately one-third of patients would become biochemically cured of the disease (i.e., athyroglobulinemia) and therefore, the American Thyroid Association (ATA) only recommended surgical removal of clinically significant metastatic lymph nodes to prevent future locoregional complications $[2,5,6]$. 
Other options include percutaneous ethanol injection and radiofrequency ablation (RFA) as their efficacy have been shown in several studies [7-9]. The decision for further adjuvant RAI therapy after reoperative neck dissection depends on the completeness of the dissection [5]. After that, local external beam radiation therapy (EBRT) might be considered in patients with gross unresectable, residual recurrence in the thyroid bed or lateral neck area. Adjuvant external beam radiation in patients with residual microscopic disease could achieve a higher 10-year local relapse-free rate (93\% versus $78 \%)$ and disease free survival (100\% versus 95\%) compared with nonradiated patients [10].

In terms of treating patients with distant metastasis, surgical resection is often not the first treatment modality unless a patient has a solitary metastasis which is located near to or in a vital area such as the brain or vertebra. EBRT might be considered in patients with unresectable painful bone metastasis or metastatic lesion which might develop future debilitating complication, for example, fracture, neurological symptoms, compressing or invading of vital structures. In patient with brain metastasis not amendable to surgical resection, whole brain irradiation for multiple lesion or gamma knife radiosurgery for selected patients are acceptable options $[5,11]$. RAI is often used as the first-line treatment for patients with distant metastases because it is highly effective in the treatment of small sized distant metastases. Although pulmonary pneumonitis and fibrosis are potential complications which could arise from repeated high-dose RAI treatment, it is recommended that pulmonary micrometastases should be treated with RAI (100-200 mCi) therapy and repeated every 6-12 months so long as the disease continues to concentrate RAI (i.e., RAIavid) and responds clinically. RAI is generally recommended in patients with nonpulmonary RAI-avid distant metastases, although it might be less effective than pulmonary RAI-avid metastases $[2,5]$.

As a result, one of the most controversial and difficult issues in treating advanced PTC is how to manage nonRAI-avid disease or RAI-refractory. A patient is defined as having RAI-refractory disease if there is at least one lesion without RAI uptake or a lesion has progressed within a year following RAI treatment or persisted after the administration of a cumulative activity of more than $600 \mathrm{mCi}$. The current evidence suggests that RAI is of little benefit in patients with RAI-refractory disease [12, 13]. Furthermore, repeated dosage of RAI is associated with dose related complications like salivary gland damage, dental caries, nasolacrimal duct obstruction, and secondary malignancy [5, 14]. Although in the setting of a negative diagnostic RAI scan, small metastases may demonstrate a small measurable benefit to RAI (in terms of decreased $\mathrm{Tg}$ ), it is of no use at all in large-sized metastases $[12,13]$. Therefore, RAI is generally not recommended in RAI-refractory disease and the current treatment options are mainly restricted to conservative treatment, metastectomy, symptomatic control (e.g., drainage of effusions), endobronchial laser ablation, and/or external beam radiation in locally advanced carcinoma. Although age and patient performance status are important considerations when deciding on which treatment option might be preferred, with better understanding and advances in the molecular biology that underlies the development and progression of advanced PTC, many new molecular targeted drugs have been examined or are being examined in the setting of a clinical trial. To date, the available drugs have been targeting two specific molecular pathways in thyroid oncogenesis, namely the mitogen-activated protein kinase (MAPK) pathway and the phosphatidyl-inositoltri-phosphate kinase (PI3K) pathway. Figure 1 shows the main signaling pathways involved in thyroid oncogenesis. Redifferentiation therapy is a potential alternative for RAIrefractory disease. Redifferentiating agents could potentially reactivate the RAI uptake ability of DTC. The aim of the present paper is to evaluate the efficacy of these new molecular targeted drugs as well as redifferentiation therapy in the treatment of RAI-refractory advanced or metastatic PTC by reviewing the current literature.

\section{Approach to Patients with RAI-Refractory Advanced PTC}

Before starting novel therapy, patients with RAI refractory disease should be accurately characterized in terms of age, performance status, histology, disease extent and location, and progression rate [16]. Diagnostic procedures should consist of neck ultrasonography to look for possible concomitant locoregional disease, thin-cut CT neck, thorax, and abdomen to look for other distant metastases and MRI brain for small brain metastases. FDG-PET may also be employed because it helps to localize disease and prognosticate patient risk [36]. For patients with neoplastic foci and high FDG uptakes, local therapy such as radical resection, RFA might be considered as these high FDG-uptake foci are likely to be more aggressive, less differentiated and have higher growth rate [37]. In terms of measuring treatment response, the response evaluation criteria in solid tumors (RECIST) criteria are often used. This is carried out by repeating standardized imaging (usually CT or MRI) every 6 months. Interestingly, there is no evidence to suggest that novel treatment such as targeted therapy should be better given at an early stage than a later stage when the tumor might be larger in size. As most patients with RAI-refractory disease might be asymptomatic for a long period of time, the benefits of targeted therapy must not be outweighed by the drug toxicities and side effects. Therefore, targeted drug is usually commenced when there is documented disease progression by standardized imaging.

\section{Potential Molecular Targets}

Figure 1 shows the main signaling pathways involved in thyroid oncogenesis [15]. Since rearrangements of RET (or $R E T / P T C$ ) and point mutations of RAS and BRAF are now believed to be initiating events in the carcinogenesis of PTC, most new targeted drugs have the ability of inhibiting the MAPK pathway and angiogenesis. RET/PTC rearrangements are found more frequently in classical PTC whereas $R A S$ point mutations are mostly found in the follicular variant of PTC. BRAF mutations are mostly found in less differentiated 


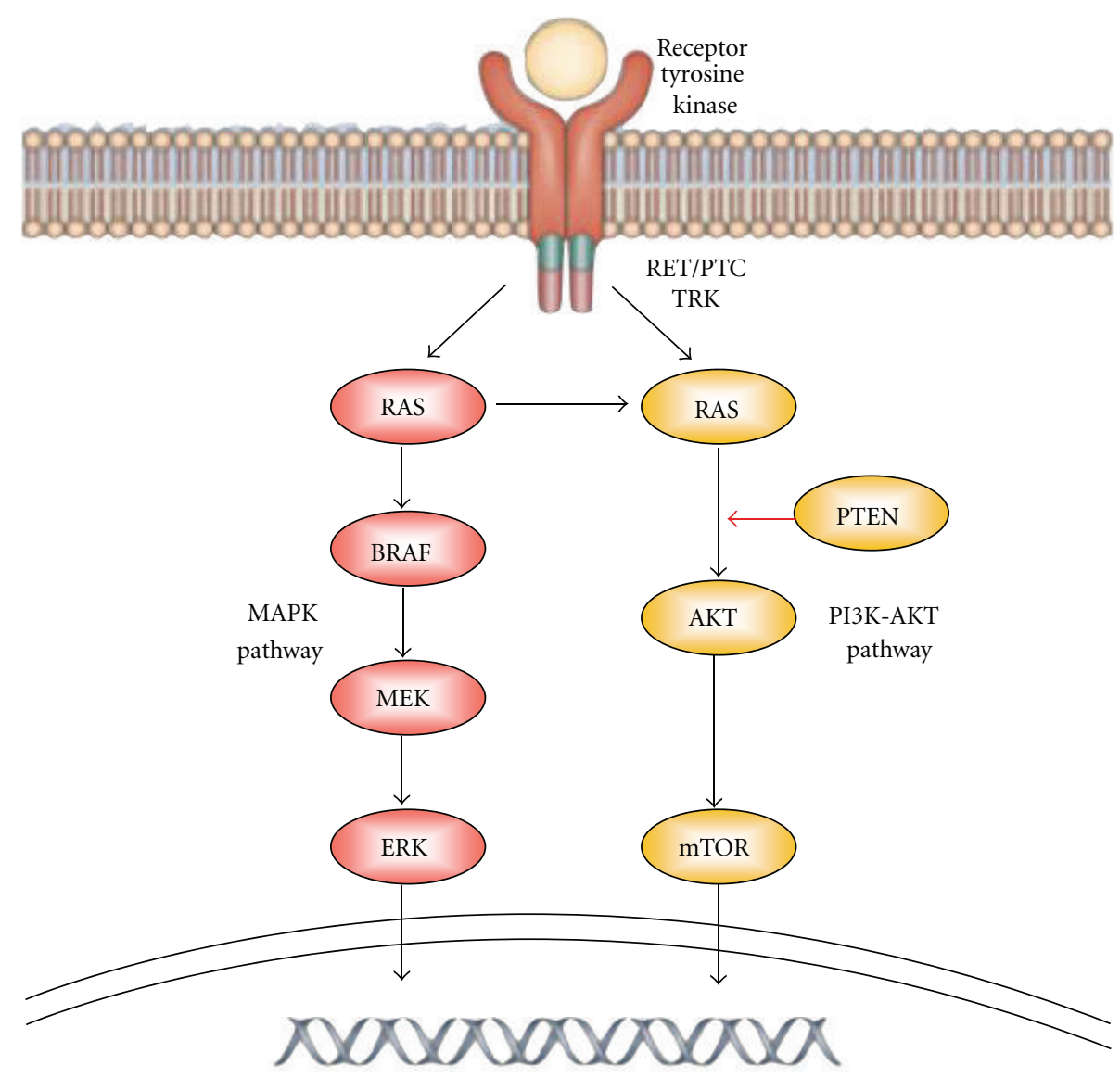

FIGURE 1: The main signaling pathways involved in thyroid carcinogenesis are the MAPK and PI3K-AKT pathway (reproduced with permission) [15].

or tall-cell variant of PTC. The PI3 K pathway may also be activated in some PTC. Other potential targets would be the angiogenic factors like various vascular endothelial growth factors (VEGF 1 and 2), fibroblast growth factor (FGF), and platelet-derived growth factor (PDGF). In vitro studies showed that anti-VEGF therapy could delay DTC growth [35]. Table 1 shows the relationship between various targeted drugs and their molecular targets.

\section{New Molecular Targeted Therapy}

Table 2 lists the results of various published trials for new targeted therapy in RAI-refractory thyroid carcinoma. Sorafenib was one of the first agents studied in RAI refractory PTC. It is an oral multi-tyrosine kinase inhibitor with multiple targets, including VEGF-R 1 to 3, $P D G F-R$, $R E T / P T C s$, and BRAF. Two American studies have published the results of using sorafenib $400 \mathrm{mg}$ twice daily in advanced PTC $[19,20]$. Gupta-Abramson et al. reported the first phase II study in advanced PTC. Of the 18 patients with advanced PTC who received treatment for a minimum of 16 weeks, 4 out of 18 patients had partial response and 10 had stable disease. In this study, the median progression-free survival was 84 weeks [19]. Kloos et al. reported another phase II study on 41 patients with metastatic papillary thyroid cancer. Of these patients, $15 \%$ had partial response and $56 \%$ had stable disease lasting for more than 6 months. The median progressive free survival was 15 months [20]. Adverse events were common, most frequent being fatigue $(60-74 \%)$, hand foot syndrome $(58-83 \%)$, diarrhea $(68-73 \%)$, and muscle pain $(28-57 \%)[19,20]$. Most of them were grade 1 or 2, and could be managed with dose reduction or drug holiday. It is interesting to note that about half the patients had to have dose reduction to improve compliance and control toxicity. Total withdrawal of treatment due to grade 3 or worse adverse events were not uncommon (about 16.6\%) [19]. Since then, 3 other studies from Europe were published. In a Netherland's study of 30 patients with DTC, $25 \%$ of patients achieved partial response. The response rate did not appear to be influenced by gender, age, initial stage, or presence of BRAF mutation. However, the radiological response was worse in patients with bone metastases [21]. The authors also studied the possibility of reinduction of RAI uptake after starting the drug but no reinduction was observed [21]. A UK study evaluated 19 patients with DTC treated with sorafenib $400 \mathrm{mg}$ twice daily and the partial 
TABLE 1: Kinase inhibitor activities of target therapies on thyroid cancer [16-18].

\begin{tabular}{|c|c|c|c|c|c|c|c|c|}
\hline \multirow{2}{*}{ Drug } & \multicolumn{8}{|c|}{ Inhibitory concentration $50\left[\mathrm{IC}_{50}\right](\mathrm{nmol} / \mathrm{L})$} \\
\hline & VEGFR-1 & VEGFR-2 & VEGFR-3 & RET & $\mathrm{BRAF}^{\mathrm{V} 600 \mathrm{E}}$ & PDGFR- $\beta$ & Kit & Others \\
\hline Sorafenib & 26 & 90 & 20 & 49 & 25 & 57 & 68 & \\
\hline Axitinib & 1.2 & 0.25 & 0.29 & & & 2 & 1.7 & \\
\hline Motesanib & 2 & 3 & 6 & 59 & & 84 & 8 & \\
\hline Sunitinib & 2 & 9 & 17 & 41 & & 39 & $1-10$ & \\
\hline Pazopanib & 10 & 30 & 47 & & & 84 & 74 & \\
\hline Lenvatinib (E7080) & 22 & 4 & 5 & 35 & & 39 & & FGFR1 (46) \\
\hline Cabozantinib (XL-184) & & 0.035 & & 4 & & & & $\operatorname{cMET}(1.8)$ \\
\hline Vandetanib & 1600 & 40 & 110 & 130 & & & & EGFR (500) \\
\hline Gefitinib & & $>10000$ & & 3700 & & & & EGFR (33) \\
\hline Selumetinib & & & & & & & & MEK1 (14) \\
\hline Dabrafenib & & & & & 0.8 & & & \\
\hline
\end{tabular}

response was $18 \%$ at 12 months [23]. Another multicenter study conducted in Spain on metastatic DTC reported the response rate in DTC and PTC were 19\% (3 out of 16 patients) and $14 \%$ ( 1 out of 7 patients), respectively. The median progression free survival was 13.5 months in patients [24]. These results appeared comparable to those reported in the two US studies.

In view of the drug toxicities, some authors attempted to reduce the standard dose and evaluated its efficacy. Chen et al. evaluated the efficacy of low dose sorafenib (200 mg twice daily) on 9 patients with RAI refractory pulmonary metastases. After three months of treatment, the partial response (by RECIST criteria) was 33\% and stable disease was achieved in $44 \%$ of patients. All adverse events were grade 1 or 2 . From this study, it appeared that low dose sorafenib could equally achieve satisfactory response in RAI-refractory PTC [22]. Based on initial success in sorafenib, a phase III international randomized controlled trial is currently underway to evaluate it in progressive RAI-refractory metastatic DTC. In this trial, patients are randomized into the placebo arm and drug arm and the primary endpoint is progression-free survival. The final results are awaiting. (NCT00984282).

Axitinib is an oral, potent selective inhibitor of VEGFRs 1,2 , and 3. It is selectively less potent in inhibiting platelet derived growth factor receptor beta and $c$-KIT. Cohen et al. published a phase II study on 60 patients with advanced thyroid cancer. Thirty patients with PTC received axitinib $5 \mathrm{mg}$ twice daily oral. Eight patients (26.7\%) had partial response. Stable disease lasting for more than 16 weeks was observed in 12 patients (40\%). Overall, the median progression-free survival was 18.1 months. Thirtytwo patients discontinued axitinib treatment either because of lack of efficacy (10 patients), or adverse effect ( 8 patients). Hypertension, proteinuria, and fatigue were most common grade 3 or worse events [25].

Motesanib (AMG-706) is a novel oral inhibitor of multiple tyrosine kinases, including VEGF receptors, $P D G F$ and KIT. In an open label phase 2 trials, 93 patients with progressive, locally advanced, or metastatic, RAI-refractory
DTC were prescribed with $125 \mathrm{mg}$ motesanib once daily orally. Fifty-seven (61\%) patients had PTC. The objective radiological response assessed was $14 \%$. Of these, $67 \%$ achieved stable disease while 35\% maintained stable disease for 24 or more weeks. In 75 patients whom had $\mathrm{Tg}$ assay, $61(81 \%)$ had reduction in Tg levels. The authors found a significant correlation between the drop in baseline $\mathrm{Tg}$ and radiological response rate. Similar to other drugs, adverse effects were a major concern. $94 \%$ of all patients experienced adverse events, and $62 \%$ had grade 3 or above adverse events. The most common adverse events were hypertension $(25 \%)$ or diarrhea (13\%) There were 2 treatment-related deaths; both were due to pulmonary hemorrhage [26].

Sunitinib is a multitargeted tyrosine kinase inhibitor of VEGFR type 1 and 2, PDGFR $\partial$, and $\beta, c$-Kit, FLTF, and RET. In a phase II study, $37.5 \mathrm{mg}$ daily sunitinib was prescribed continuously to 35 patients with FDG-avid, RAIrefractory DTC or medullary thyroid carcinoma (MTC). $28 \%$ of patients with DTC achieved a RECIST response assessed by 3 monthly CT scan. The median time to progress was 12.8 months in this series. The functional response was also analyzed in this study. In 19 patients with DTC who underwent PET/CT scan before and after 7 days of sunitinib therapy, the percentage change of SUV were $-13.5 \%, 17.5 \%$, and $9.0 \%$ for patients with RECIST response, with stable disease and with progressive disease respectively. There was a significant correlation between SUV changes and changes in RECIST criteria $(P=0.005)$. Despite satisfactory functional and RECIST response, hematological and other treatmentrelated adverse events were also common. Upto $34 \%$ of patients suffered grade 3 or worse hematological side effects including leukopenia, neutropenia. Other common adverse effects ( $\geq$ grade 3 ) including diarrhea (17\%), hand foot syndrome (17\%), and fatigue (11\%) [27]. Cohen et al. reported another series of 43 patients with either DTC or MTC. In 37 patients with DTC, response rate was 13\% and $68 \%$ had stable disease. Grade 3/4 haematological adverse effect were comparably common [28].

Pazopanib (Votrient) is a tyrosine kinase inhibitor targeting VEGFR, PDGF, and $c$-KIT. It has an antiangiogenic effect 
TABLE 2: Study on target therapy in radioiodine-refractory papillary thyroid cancer.

\begin{tabular}{|c|c|c|c|c|c|c|c|}
\hline \multirow[b]{2}{*}{ Author } & \multirow[b]{2}{*}{ Study } & \multirow[b]{2}{*}{ Agent } & \multirow[b]{2}{*}{$\begin{array}{l}\text { Number of patients } \\
\text { [type] }\end{array}$} & \multicolumn{4}{|c|}{ Result } \\
\hline & & & & $\begin{array}{c}\text { Response rate } \\
(\%)\end{array}$ & $\begin{array}{l}\text { Stabilization } \\
\quad(\%)\end{array}$ & $\begin{array}{c}\text { Progression-free } \\
\text { survival } \\
\text { (months) }\end{array}$ & $\begin{array}{c}\text { Discontinuation } \\
\text { due to adverse } \\
\text { effect }\end{array}$ \\
\hline $\begin{array}{l}\text { Gupta-Abramson } \\
\text { et al. [19] }\end{array}$ & Phase II & Sorafenib & $\begin{array}{l}30 \text { [DTC and MTC] } \\
\text { (i) DTC: } 27 / 30 \\
\text { (ii) PTC: } 18 / 30\end{array}$ & $\begin{array}{c}23 \% \\
25.9 \% \\
22.2 \% \\
\end{array}$ & $\begin{array}{c}53 \% \\
55.6 \% \\
61.1 \% \\
\end{array}$ & $\begin{array}{l}18.2(79 \text { weeks }) \\
19.3 \text { (84 weeks) }\end{array}$ & $16.7 \%$ \\
\hline Kloos et al. [20] & Phase II & Sorafenib & 41 [PTC] & $15 \%$ & $56 \%$ ( $\geq 6$ months) & 15 & - \\
\hline $\begin{array}{l}\text { Hoftijzer et al. } \\
{[21]}\end{array}$ & Phase II & Sorafenib & $\begin{array}{l}31 \text { [DTC] } \\
\text { PTC: } 14 / 31\end{array}$ & $25 \%$ & $34 \%$ (26 weeks) & 13.3 (58 weeks) & $19.4 \%$ \\
\hline Chen et al. [22] & Phase II & Sorafenib & $9[\mathrm{PTC}]$ & $33 \%$ & $44 \%$ & 9.6 (42 weeks) & 0 \\
\hline Ahmed et al. [23] & Phase II & Sorafenib & $\begin{array}{l}34 \text { [MTC and DTC] } \\
\text { PTC: } 19 / 34\end{array}$ & $\begin{array}{l}15 \% \\
18 \% \\
\end{array}$ & $74 \%$ (6 months) & - & $5.9 \%$ \\
\hline $\begin{array}{l}\text { Capdevila et al. } \\
{[24]}\end{array}$ & Phase II & Sorafenib & $\begin{array}{l}34^{* *} \\
\text { (i) DTC: } 16 / 34 \\
\text { (ii) PTC: } 7 / 34\end{array}$ & $\begin{array}{l}32 \% \\
19 \% \\
14 \% \\
\end{array}$ & $\begin{array}{c}41 \% \text { (6 months) } \\
50 \% \\
43 \% \\
\end{array}$ & 13.5 & - \\
\hline Cohen et al. [25] & Phase II & Axitinib & $\begin{array}{l}60[\mathrm{DTC}] \\
\text { PTC: } 30 / 60\end{array}$ & $\begin{array}{c}30 \% \\
26.7 \% \\
\end{array}$ & $\begin{array}{c}38 \%(\geq 16 \text { weeks }) \\
40 \%\end{array}$ & 18.1 & $13 \%$ \\
\hline $\begin{array}{l}\text { Sherman et al. } \\
{[26]}\end{array}$ & Phase II & Motesanib & $\begin{array}{l}93 \text { [DTC] } \\
\text { PTC: } 57 / 93\end{array}$ & $14 \%$ & $35 \%$ (24 weeks) & 9.3 & $13 \%$ \\
\hline Carr et al. [27] & Phase II & Sunitinib & $\begin{array}{l}35 \text { [DTC and MTC] } \\
\text { (i) DTC: } 28 / 35 \\
\text { (ii) PTC: } 18 / 35\end{array}$ & $\begin{array}{l}31 \% \\
28 \%\end{array}$ & $\begin{array}{l}46 \% \\
68 \%\end{array}$ & 12.8 & $11.4 \%$ \\
\hline Cohen et al. [28] & Phase II & Sunitinib & $31[\mathrm{DTC}]$ & $13 \%$ & $68 \%$ & - & - \\
\hline Bible et al. [29] & Phase II & Pazopanib & $\begin{array}{l}37 \text { [DTC] } \\
\text { PTC: } 15 / 37\end{array}$ & $\begin{array}{l}49 \% \\
33 \% \\
\end{array}$ & - & 11.7 & $5.4 \%$ \\
\hline $\begin{array}{l}\text { Sherman et al. } \\
{[30]}\end{array}$ & Phase II & Lenvatinib & $\begin{array}{l}58 \text { [DTC] } \\
\text { PTC: } 43 / 58\end{array}$ & $50 \%$ & $36 \%$ & 13.3 & $23 \%$ \\
\hline $\begin{array}{l}\text { Cabanillas et al. } \\
{[31]}\end{array}$ & Phase II & Cabozantinib & 15 [DTC] & $53 \%$ & $40 \%$ & - & - \\
\hline $\begin{array}{l}\text { Leboulleux et al. } \\
\text { [32] }\end{array}$ & $\begin{array}{c}\text { RCT, } \\
\text { phase II }\end{array}$ & Vandetanib & $\begin{array}{l}72 \text { versus } 73 \text { [DTC] } \\
\text { PTC: } 25 \text { versus } 24\end{array}$ & $8.3 \%$ versus $5.5 \%$ & $56 \%$ versus $36 \% *$ & $\begin{array}{r}11.1 \text { versus } 5.8^{*} \\
16.2 \text { versus } 5.9 \\
\end{array}$ & $33 \%$ versus $6 \%$ \\
\hline Pennell et al. [33] & Phase II & Gefitinib & $\begin{array}{l}27^{* *} \\
\text { PTC: } 11 / 27\end{array}$ & $0 \%$ & $24 \%$ (6 months) & 3.7 & $7.4 \%$ \\
\hline Hayes et al. [34] & Phase II & Selumetinib & 32 [PTC] & $3 \%$ & $36 \%$ (24 weeks) & 7.4 & - \\
\hline $\begin{array}{l}\text { Falchook et al. } \\
\text { [35] }\end{array}$ & Phase I & Dabrafenib & $14[\mathrm{PTC}]$ & $21.4 \%$ & - & - & 0 \\
\hline
\end{tabular}

DTC: differentiated thyroid cancer, PTC: papillary thyroid cancer, MTC: medullary thyroid cancer; RCT: randomized controlled trial.

$* P<0.05$.

** Included differentiated, medullary, and anaplastic thyroid carcinoma.

on RAI-refractory DTC. In a phase II study on 37 patients with progressive radioiodine refractory DTC over previous 6 months, partial response was achieved in 18 patients. Response rate was $49 \%$ and $33 \%$ (5 out of $15 \%$ ) in patients with DTC and PTC, respectively. $66 \%$ of patients were likely to respond lasting for more than 1 year. The response rate was highest among reports of different agent. Adverse effects were common but generally well tolerate. Grade 3 or worse adverse effect was not common, and the commonest was deranged liver function tests (4 patients had raised ALT concentration). Two patients had serious hemorrhagic events (grade 3 lower gastro-intestinal bleeding, and grade 4 intracranial bleeding in the absence of brain metastasis or hypertension) and so had to discontinue treatment [29].
Lenvatinib (E7080) is an oral tyrosine kinase inhibitor targeting VEGFR 1-3, FGFR 1-4, RET, KIT, and PDGFR $\beta$. In an international phase II study, 58 patients with advanced progressive DTC were enrolled. Half of them achieved partial response on assessment. For the subgroup which had prior VEGFR inhibitors, $41 \%$ had a response whereas those without prior treatment, $54 \%$ had a response. However, because adverse effect was common, $23 \%$ of patients had to withdraw and 35\% had to have a dose reduction [30].

Cabozantinib (XL84) is an oral potent inhibitor of $c M E T$ (MET is a membrane receptor that is essential for embryonic development and wound healing), VEGFR2, and RET and is currently undergoing a clinical trial. The results of the phase I trial of this drug appeared promising with 8/15 (53\%) 
patients having confirmed partial response and $6(40 \%)$ had stable disease [31]. It is worth noting that the majority of these patients had prior VEGFR inhibitors. Grades 3 , and 4 adverse effects were comparable to other VEGFR inhibitors and included diarrhea (20\%), hypertension (13\%), and hand foot syndrome (13\%) [31].

Vandetanib, a tyrosine kinase inhibitor of RET, VEGFR, and EGFR signaling, was the first targeted therapy subjected to large scale multicenter randomized clinical trial [32]. 145 patients with radioiodine refractory differentiated thyroid cancer were enrolled into the trial. Seventy-two patients, including 25 with PTC, were allocated to vandetanib $300 \mathrm{mg}$ per day group and 73 patients, including 24 with PTC were allocated to placebo group. Patients in vandetanib group (median: 11.1 months (95\% CI 7.7-14.0)) had longer progression-free survival than placebo group [median: 5.9 months (95\% CI 4.0-8.9) ( $P=0.017)$. For patient with PTC, median progression-free survival was 16.2 months (95\% CI 8.4-22.6) in vandetanib group and 5.9 months (95\% CI 3.0-11.5) in placebo group. Although it was not statistically significant, there was a tendency for clinical benefit (Hazard ratio: $0.52,95 \% \mathrm{CI} 0.26-1.02, P=0.056)$. However, there was no difference in overall survival (Hazard ratio: 0.83, 95\% CI $0.52-1.33, P=0.42)$. Most frequent adverse events were diarrhea (74\%) and hypertension (34\%). The incidence of grade 3 or worse adverse events were higher in vandetanib group (53\%, 39/73 patients) than placebo group (19\%, 14/72 patients), while the commonest were QTc prolongation (14\%) and diarrhea (10\%) [32].

Since EGFR mutations were found in some PTC, Gefitinib, an inhibitor of EGFR tyrosine kinase, had been evaluated in a phase II study for advanced PTC. Pennell et al. reported the results of 27 patients with 11 of them suffering from PTC. There was no objective response observed. $24 \%$ had stable disease after 6 months of treatment. Five patients with stable disease had significant drop in thyroglobulin (>90\% drop) maintained over 3 months. However, no patient achieved partial response by criteria. The authors concluded that this drug had limited biological activity of around $12 \%$ only [33].

Other than antiangiogenic therapies, drugs targeting specific molecular pathway, namely MAPK and PI3K, were studied in phase I, and II studies. Selumetinib is a selective oral non-ATP competitive small molecule inhibitor of $M A P K$ kinases, $M E K 1 / 2$. In in vitro studies, Selumetinib was potent in PTC cell line with V600E BRAF mutation. It had been recently evaluated in a multicenter phase II study in patient with radioiodine refractory papillary thyroid carcinoma. Selumetinib $100 \mathrm{mg}$ twice daily was prescribed to patients with document progression in the last 12 months. Only 1 patient (3\%) achieved partial response and 21 (54\%) had stable disease. Common grade 3 to 4 toxicities included rash $(18 \%)$, fatigue $(8 \%)$, diarrhea $(5 \%)$, and peripheral edema (5\%). In BRAF evaluated patient, BRAF mutant had a longer median progression free survival than $B R A F$ widetype tumor, though it was not statistically significant (33 versus 11 weeks, $P=0.3$ ) [34].
In a recent published phase I trial, Dabrafenib, inhibitor of BRAF kinase for BRAF mutant, had showed its antitumor activity in 14 patients with $B R A F$ mutant PTC. Three of nine assessable patients achieved partial response. Its adverse effect was less common and more tolerable. The most common grade 2 or worse adverse effects were cutaneous squamous cell carcinoma (11\%), fatigue ( $8 \%)$, and pyrexia $(6 \%)$ [35].

In addition to agents which target MAPK and PI3 KAKT pathways, $m$ TOR inhibitors have been widely studied recently. In vitro studies, $m$ TOR pathway activation have been found in aggressive and BRAF mutated PTC [38, 39]. Phase I study of daily everolimus plus low dose weekly cisplatin reported 1 out of 4 patients achieved prolong stable disease for 6 months [40]. Sherman et al. reported phase II study on use of combination of sorafenib and temsirolimus in 37 patients radioiodine refractory thyroid carcinoma. $21.6 \%$ patients had partial response and $56.7 \%$ had stable after median time on treatment of 206 days [41].

Studies on combination of target therapy like everolimus/ lenalidomide, pazopanib/GSK1120212 (MEK inhibitor), and pimasertib (MEK inhibitor)/SAR245409 (PI3K/mTOR inhibitors) are ongoing and hopefully, results would become available in the near future [42-44].

Majority of studies focused on patients with PTC or small subgroup of follicular thyroid carcinoma (FTC) patients (Table 2); current evidences on treatment specific on FTC were limited. Applicability and efficacy of target therapies on patient with follicular thyroid carcinoma have to be further evaluated.

\section{Redifferentiation of RAI-Refractory Thyroid Carcinoma}

Redifferentiation remains an ongoing area of research in RAI-refractory thyroid carcinoma because development of de-differentiated phenotype of DTC leads to loss or absence of radioiodine uptake ability. Redifferentiating agents could potentially reactivate the RAI uptake ability of thyroid carcinoma. Retinoids, chemically related to Vitamin A, were the first widely studied agents for potential application on redifferentiation in radioiodine refractory thyroid cancer.

Early in vitro studies showed that decreased expression of retinoic acid receptor in thyroid cancer cell [45]. Treatment with retinoids could upgrade the sodium-iodine symporter (NIS) and thus induce redifferentiation and iodine uptake by tumor cell. Grüning et al. reported their series on 14 RAI-refractory patients and showed that 2/14 showed slightly increased uptake [46]. Similar results have been found by other authors. Short et al. reported the results of 16 patients with RAI uptake negative DTC. Patients were prescribed oral isotretinoid $1.5 \mathrm{mg} / \mathrm{kg} /$ day for 8 weeks. RAI scan repeated 2 weeks later reviewed only $1 / 16(6.25 \%)$ patient had increased radio-iodine uptake [47]. Simon et al. reported a more promising result of using 13-cis-retinoic acid as a sole treatment. Fifty patients with RAI-refractory DTC were treated with 13-cis-retinoic acid at dosage of $1.5 \mathrm{mg} / \mathrm{kg}$ daily over 5 weeks. Thirteen (26\%) showed marked increase in RAI 
uptake while 8 patients (16\%) showed mild increased in RAI uptake in the post-therapy scan. Tumor size was assessed in 37 patients and of these, 6 had tumor regression while 22 had static disease. As a whole, 19 (38\%) patients showed either response or stable in clinical response. However, further analysis reviewed that increased RAI uptake did not always correlate with clinical response [48]. More recently, Oh et al. incorporated retinoic acid into RAI ablation to treat RAI refractory PTC. Oral isotretinoid was prescribed for 6 weeks at $1-1.5 \mathrm{mg} / \mathrm{kg}$ daily and then followed by single dose of RAI. At 6-month follow up, 1 patient showed completed response, 9 had partial response, 9 had stable and 28 had progressive disease. Overall response rate was $21.3 \%$ [49].

Due to the limited benefits, routine use of retinoic acid alone is not recommended. Preliminary study showed enlightening clinical response in refractory cancer results only in combination therapy. Therefore, further studies are indicated to evaluate its clinical application, dosage, duration, and combination regimen.

Thiazolidinedione, an antidiabetic medication, is another potential redifferentiation agent. It acts as a peroxisome proliferator-activated receptor gamma agonist. It was shown to have both redifferentiation and anti-proliferative effects in in vitro study of thyroid cancer cells [50]. In an open phase II trial of 20 patients with Tg-positive RAI-refractory DTC, $25 \%$ (5/20) regained RAI uptake. $60 \%(12 / 20)$ had stable disease and $15 \%(3 / 20)$ had reduction in tumor marker. Overall, 5 patients had a partial response in terms of decreased Tg or positive RAI uptake on scan. However, no complete or partial response was noted in any patients according to RECIST criteria [51]. Other agents, including histone deacetylase inhibitor, (e.g., valproic acid, trichostatin, and depsipeptide), DNA demethylating agents, (e.g., 5-azacytidine), and arsenic trioxide, had shown differentiation inducing properties in thyroid cancer cells in in vitro studies [52-55]. Potential clinical application had to be further validated by future studies.

\section{Conclusion}

Managing RAI-refractory advanced or metastatic PTC remains challenging. Given the fact that RAI is of little benefit in this group of patients, various treatment options such as observation, symptomatic control, surgery, local ablative therapy, metastectomy, and EBRT might be considered. New molecular targeted drugs including tyrosine kinase inhibitors and redifferentiation drugs are new promising therapeutic options for this specific group of patients.

\section{References}

[1] Hong Kong Cancer Registry, "Cancer incidence and mortality in Hong Kong 1983-2006,” Hong Kong Cancer Registry, Hong Kong, 2012, http://www3.ha.org.hk/cancereg/.

[2] B. H. Lang, K. P. Wong, and K. Y. Wan, "Postablation stimulated thyroglobulin level is an important predictor of biochemical complete remission after reoperative cervical neck dissection in persistent/recurrent papillary thyroid Carcinoma," Annals of Surgical Oncology. In press.
[3] H. Tala and R. M. Tuttle, "Contemporary post surgical management of differentiated thyroid carcinoma," Clinical Oncology, vol. 22, no. 6, pp. 419-429, 2010.

[4] H. Wong, K. P. Wong, T. Yau et al., "Is there a role for unstimulated thyroglobulin velocity in predicting recurrence in papillary thyroid carcinoma patients with detectable thyroglobulin after radioiodine ablation?" Annals of Surgical Oncology, vol. 19, no. 11, pp. 3479-3485, 2012.

[5] D. S. Cooper, G. M. Doherty, B. R. Haugen et al., "Revised American thyroid association management guidelines for patients with thyroid nodules and differentiated thyroid cancer," Thyroid, vol. 19, no. 11, pp. 1167-1214, 2009.

[6] D. T. Hughes, A. M. Laird, B. S. Miller et al., "Reoperative lymph node dissection for recurrent papillary thyroid cancer and effect on serum thyroglobulin," Annals of Surgical Oncology, vol. 19, no. 9, pp. 2951-2957, 2012.

[7] D. E. Dupuy, J. M. Monchik, C. Decrea, and L. Pisharodi, "Radiofrequency ablation of regional recurrence from welldifferentiated thyroid malignancy," Surgery, vol. 130, no. 6, pp. 971-977, 2001.

[8] B. D. Lewis, I. D. Hay, J. W. Charboneau, B. McIver, C. C. Reading, and J. R. Goellner, "Percutaneous ethanol injection for treatment of cervical lymph node metastases in patients with papillary thyroid carcinoma," American Journal of Roentgenology, vol. 178, no. 3, pp. 699-704, 2002.

[9] K. Nakada, K. Kasai, Y. Watanabe et al., "Treatment of radioiodine-negative bone metastasis from papillary thyroid carcinoma with percutaneous ethanol injection therapy," Annals of Nuclear Medicine, vol. 10, no. 4, pp. 441-444, 1996.

[10] R. W. Tsang, J. D. Brierley, W. J. Simpson et al., "The effects of surgery, radioiodine, and external radiation therapy on the clinical outcome of patients with differentiated thyroid carcinoma," Cancer, vol. 82, no. 2, pp. 375-388, 1998.

[11] M. Luster, F. Lippi, B. Jarzab et al., "rhTSH-aided radioiodine ablation and treatment of differentiated thyroid carcinoma: a comprehensive review," Endocrine-Related Cancer, vol. 12, no. 1, pp. 49-64, 2005.

[12] F. Pacini, L. Agate, R. Elisei et al., "Outcome of differentiated thyroid cancer with detectable serum Tg and negative diagnostic ${ }^{131}$ I whole body scan: comparison of patients treated with high ${ }^{131}$ I activities versus untreated patients," The Journal of Clinical Endocrinology \& Metabolism, vol. 86, no. 9, pp. 40924097, 2001.

[13] V. Fatourechi, I. D. Hay, H. Javedan, G. A. Wiseman, B. P. Mullan, and C. A. Gorman, "Lack of impact of radioiodine therapy in tg-positive, diagnostic whole-body scan-negative patients with follicular cell-derived thyroid cancer," The Journal of Clinical Endocrinology \& Metabolism, vol. 87, no. 4, pp. 1521-1526, 2002.

[14] B. H. Lang, I. O. L. Wong, K. P. Wong et al., "Risk of second primary malignancy in differentiated thyroid carcinoma treated with radioactive iodine therapy," Surgery, vol. 151, no. 6, pp. 844-850, 2012.

[15] Y. E. Nikiforov and M. N. Nikiforova, "Molecular genetics and diagnosis of thyroid cancer," Nature Reviews Endocrinology, vol. 7, no. 10, pp. 56-80, 2011.

[16] M. Schlumberger and S. I. Sherman, "Approach to the patient with advanced differentiated thyroid cancer," European Journal of Endocrinology, vol. 166, no. 1, pp. 5-11, 2012.

[17] F. Pacini, L. Brilli, and S. Marchisotta, "Targeted therapy in radioiodine refractory thyroid cancer," Quarterly Journal of Nuclear Medicine and Molecular Imaging, vol. 53, no. 5, pp. 520-525, 2009. 
[18] E. Grande, J. José Díez, C. Zafon et al., "Thyroid cancer: molecular aspects and new therapeutic strategies," Journal of Thyroid Research, vol. 2012, Article ID 847108, 10 pages, 2012.

[19] V. Gupta-Abramson, A. B. Troxel, A. Nellore et al., "Phase II trial of sorafenib in advanced thyroid cancer," Journal of Clinical Oncology, vol. 26, no. 29, pp. 4714-4719, 2008.

[20] R. T. Kloos, M. H. Shah, M. D. Ringel et al., "Phase II trial of sorafenib in metastatic thyroid cancer," Journal of Clinical Oncology, vol. 27, no. 10, pp. 1675-1684, 2009.

[21] H. Hoftijzer, K. A. Heemstra, H. Morreau et al., "Beneficial effects of sorafenib on tumor progression, but not on radioiodine uptake, in patients with differentiated thyroid carcinoma," European Journal of Endocrinology, vol. 161, no. 6, pp. 923-931, 2009.

[22] L. Chen, Y. Shen, Q. Luo, Y. Yu, H. Lu, and R. Zhu, "Response to sorafenib at a low dose in patients with radioiodine-refractory pulmonary metastases from papillary thyroid carcinoma," Thyroid, vol. 21, no. 2, pp. 119-124, 2011.

[23] M. Ahmed, Y. Barbachano, A. Riddell et al., "Analysis of the efficacy and toxicity of sorafenib in thyroid cancer: a phase II study in a UK based population," European Journal of Endocrinology, vol. 165, no. 2, pp. 315-322, 2011.

[24] J. Capdevila, L. Iglesias, I. Halperin et al., "Sorafenib in metastatic thyroid cancer," Endocrine-Related Cancer, vol. 19, no. 2, pp. 209-216, 2012.

[25] E. E. W. Cohen, L. S. Rosen, E. E. Vokes et al., "Axitinib is an active treatment for all histologic subtypes of advanced thyroid cancer: results from a phase II study," Journal of Clinical Oncology, vol. 26, no. 29, pp. 4708-4713, 2008.

[26] S. I. Sherman, L. J. Wirth, J. P. Droz et al., "Motesanib diphosphate in progressive differentiated thyroid cancer," The New England Journal of Medicine, vol. 359, no. 1, pp. 31-42, 2008.

[27] L. L. Carr, D. A. Mankoff, B. H. Goulart et al., "Phase II study of daily sunitinib in FDG-PET-positive, iodine-refractory differentiated thyroid cancer and metastatic medullary carcinoma of the thyroid with functional imaging correlation," Clinical Cancer Research, vol. 16, no. 21, pp. 5260-5268, 2010.

[28] E. E. Cohen, B. M. Needles, K. J. Cullen et al., "Phase 2 study of sunitinib in refractory thyroid cancer," Journal of Clinical Oncology, vol. 26, no. 15, supplement, ASCO Meeting Abstracts 6025, 2008.

[29] K. C. Bible, V. J. Suman, J. R. Molina et al., "Efficacy of pazopanib in progressive, radioiodine-refractory, metastatic differentiated thyroid cancers: results of a phase 2 consortium study," The Lancet Oncology, vol. 11, no. 10, pp. 962-972, 2010.

[30] S. I. Sherman, B. Jarzab, M. E. Cabanillas et al., "A phase II trial of the multitargeted kinase inhibitor E7080 in advanced radioiodine (RAI)-refractory differentiated thyroid cancer (DTC)," Journal of Clinical Oncology, vol. 29, no. 15, supplement, ASCO Meeting Abstracts 5503, 2011.

[31] M. E. Cabanillas, M. S. Brose, D. A. Ramies et al., "Antitumor activity of cabozantinib (XL184) in a cohort of patients (pts) with differentiated thyroid cancer (DTC)," Journal of Clinical Oncology, vol. 30, no. 15, supplement, ASCO Meeting Abstracts 5547, 2012.

[32] S. Leboulleux, L. Bastholt, T. Krause et al., "Vandetanib in locally advanced or metastatic differentiated thyroid cancer: a randomised, double-blind, phase 2 trial," The Lancet Oncology, vol. 13, no. 9, pp. 897-905, 2012.

[33] N. A. Pennell, G. H. Daniels, R. I. Haddad et al., "A phase II study of gefitinib in patients with advanced thyroid cancer," Thyroid, vol. 18, no. 3, pp. 317-323, 2008.
[34] D. N. Hayes, A. S. Lucas, T. Tanvetyanon et al., "Phase II efficacy and pharmacogenomic study of Selumetinib (AZD6244, ARRY-142886) in iodine-131 refractory papillary thyroid carcinoma with or without follicular elements," Clinical Cancer Research, vol. 18, no. 7, pp. 2056-2065, 2012.

[35] G. S. Falchook, G. V. Long, R. Kurzrock et al., "Dabrafenib in patients with melanoma, untreated brain metastases, and other solid tumours: a phase 1 dose-escalation trial," The Lancet, vol. 379, no. 9829, pp. 1893-1901, 2012.

[36] B. H. H. Lang and T. T. Law, "The role of 18F-fluorodeoxyglucose positron emission tomography in thyroid neoplasms," Oncologist, vol. 16, no. 4, pp. 458-466, 2011.

[37] W. Wang, S. M. Larson, M. Fazzari et al., "Prognostic value of $[18 \mathrm{~F}]$ fluorodeoxyglucose positron emission tomographic scanning in patients with thyroid cancer," The Journal of Clinical Endocrinology \& Metabolism, vol. 85, no. 3, pp. 11071113, 2000.

[38] A. Faustino, J. P. Couto, H. Pópulo et al., "mTOR pathway overactivation in BRAF mutated papillary thyroid carcinoma," The Journal of Clinical Endocrinology \& Metabolism, vol. 97, no. 7, pp. E1139-E1149, 2012.

[39] M. A. Kouvaraki, C. Liakou, A. Paraschi et al., "Activation of mTOR signaling in medullary and aggressive papillary thyroid carcinomas," Surgery, vol. 150, no. 6, pp. 1258-1265, 2011.

[40] M. G. Fury, E. Sherman, S. Haque et al., "A phase I study of daily everolimus plus low-dose weekly cisplatin for patients with advanced solid tumors," Cancer Chemotherapy and Pharmacology, vol. 69, no. 3, pp. 591-598, 2012.

[41] E. J. Sherman, A. L. Ho, M. G. Fury et al., "A phase II study of temsirolimus/sorafenib in patients with radioactive iodine (RAI)-refractory thyroid carcinoma," Journal of Clinical Oncology, vol. 30, no. 15, supplement, ASCO Meeting Abstracts 5514, 2012.

[42] T. K. Owonikoko, R. D. Harvey, J. S. Kauh et al., "A phase I study of the safety and pharmacodynamic effects of everolimus in combination with lenalidomide in patients with advanced solid malignancies," Journal of Clinical Oncology, vol. 30, no. 15, supplement, ASCO Meeting Abstracts 2576, 2012.

[43] S. R. Ahmed, N. S. Azad, D. Wilmot Ball et al., "A phase I study determining the safety and tolerability of combination therapy with pazopanib, a VEGFR/PDGFR/raf inhibitor, and GSK1120212, a MEK inhibitor, in advanced solid tumors enriched with patients with advanced differentiated thyroid cancer," Journal of Clinical Oncology, vol. 30, no. 15, supplement, ASCO Meeting Abstracts TPS3117, 2012.

[44] J. R. Infante, L. Gandhi, G. Shapiro et al., "Phase lb combination trial of a MEK inhibitor, pimasertib (MSC1936369B), and a PI3K/mTOR inhibitor, SAR245409, in patients with locally advanced or metastatic solid tumors," Journal of Clinical Oncology, vol. 30, no. 15, supplement, ASCO Meeting Abstracts TPS3118, 2012.

[45] L. A. Hansen, C. C. Sigman, F. Andreola, S. A. Ross, G. J. Kelloff, and L. M. De Luca, "Retinoids in chemoprevention and differentiation therapy," Carcinogenesis, vol. 21, no. 7, pp. 1271-1279, 2000.

[46] T. Grüning, C. Tiepolt, K. Zöphel, J. Bredow, J. Kropp, and W. G. Franke, "Retinoic acid for redifferentiation of thyroid cancer-does it hold its promise?" European Journal of Endocrinology, vol. 148, no. 4, pp. 395-402, 2003.

[47] S. C. Short, A. Suovuori, G. Cook, G. Vivian, and C. Harmer, "A phase II study using retinoids as redifferentiation agents to increase iodine uptake in metastatic thyroid cancer," Clinical Oncology, vol. 16, no. 8, pp. 569-574, 2004. 
[48] D. Simon, C. Körber, M. Krausch et al., "Clinical impact of retinoids in redifferentiation therapy of advanced thyroid cancer: final results of a pilot study," European Journal of Nuclear Medicine and Molecular Imaging, vol. 29, no. 6, pp. 775-782, 2002.

[49] S. W. Oh, S. H. Moon, B. Y. Cho et al., "Combined therapy with ${ }^{131} \mathrm{I}$ and retinoic acid in Korean patients with radioiodine-refractory papillary thyroid cancer," European Journal of Nuclear Medicine and Molecular Imaging, vol. 38, no. 10, pp. 1798-1805, 2011.

[50] M. L. Martelli, R. Iuliano, I. Le Pera et al., "Inhibitory effects of peroxisome poliferator-activated receptor gamma on thyroid carcinoma cell growth," The Journal of Clinical Endocrinology \& Metabolism, vol. 87, no. 10, pp. 4728-4735, 2002.

[51] E. Kebebew, S. Lindsay, O. H. Clark, K. A. Woeber, R. Hawkins, and F. S. Greenspan, "Results of rosiglitazone therapy in patients with thyroglobulin-positive and radioiodine-negative advanced differentiated thyroid cancer," Thyroid, vol. 19, no. 9, pp. 953-956, 2009.

[52] N. Fortunati, M. G. Catalano, K. Arena, E. Brignardello, A. Piovesan, and G. Boccuzzi, "Valproic acid induces the expression of the $\mathrm{Na}+/ \mathrm{I}-$ symporter and Iodine uptake in poorly differentiated thyroid cancer cells," The Journal of Clinical Endocrinology \& Metabolism, vol. 89, no. 2, pp. 10061009, 2004.

[53] W. T. Shen and W. Y. Chung, "Treatment of thyroid cancer with histone deacetylase inhibitors and peroxisome proliferator-activated receptor- $\gamma$ agonists," Thyroid, vol. 15, no. 6, pp. 594-599, 2005.

[54] T. Kondo, T. Nakazawa, D. Ma et al., "Epigenetic silencing of TTF-1/NKX2-1 through DNA hypermethylation and histone H3 modulation in thyroid carcinomas," Laboratory Investigation, vol. 89, no. 7, pp. 791-799, 2009.

[55] E. Fröhlich, B. Czarnocka, P. Brossart, and R. Wahl, "Antitumor effects of arsenic trioxide in transformed human thyroid cells," Thyroid, vol. 18, no. 11, pp. 1183-1193, 2008. 


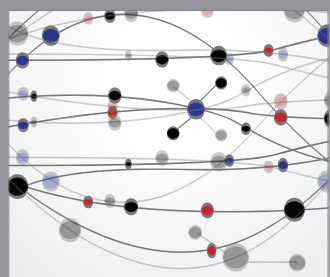

The Scientific World Journal
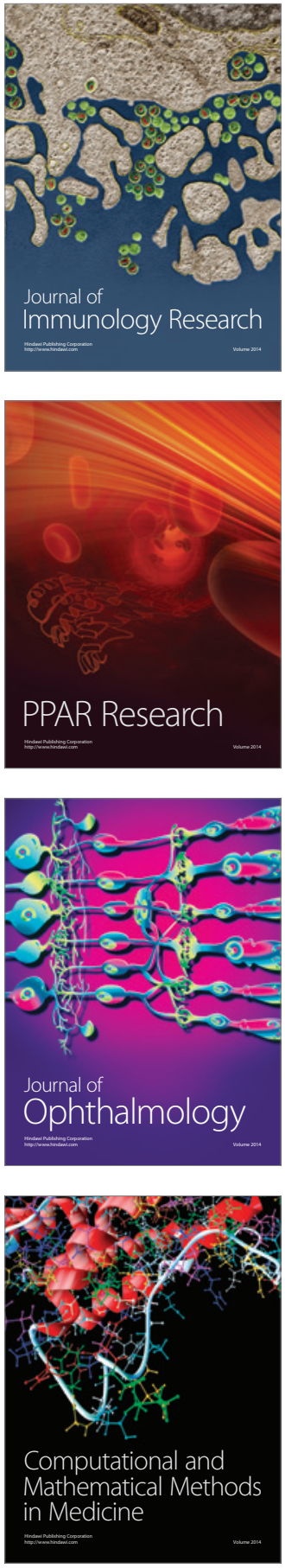

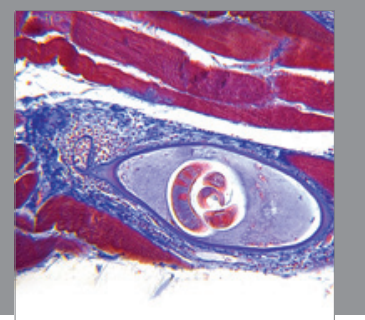

Gastroenterology

Research and Practice
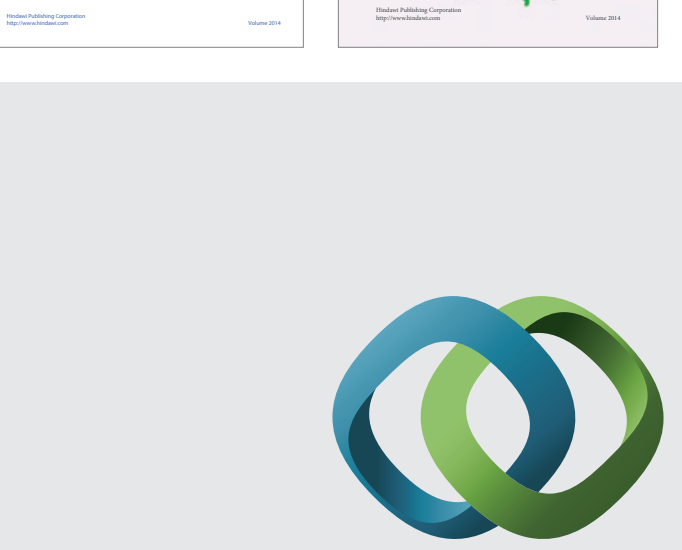

\section{Hindawi}

Submit your manuscripts at

http://www.hindawi.com
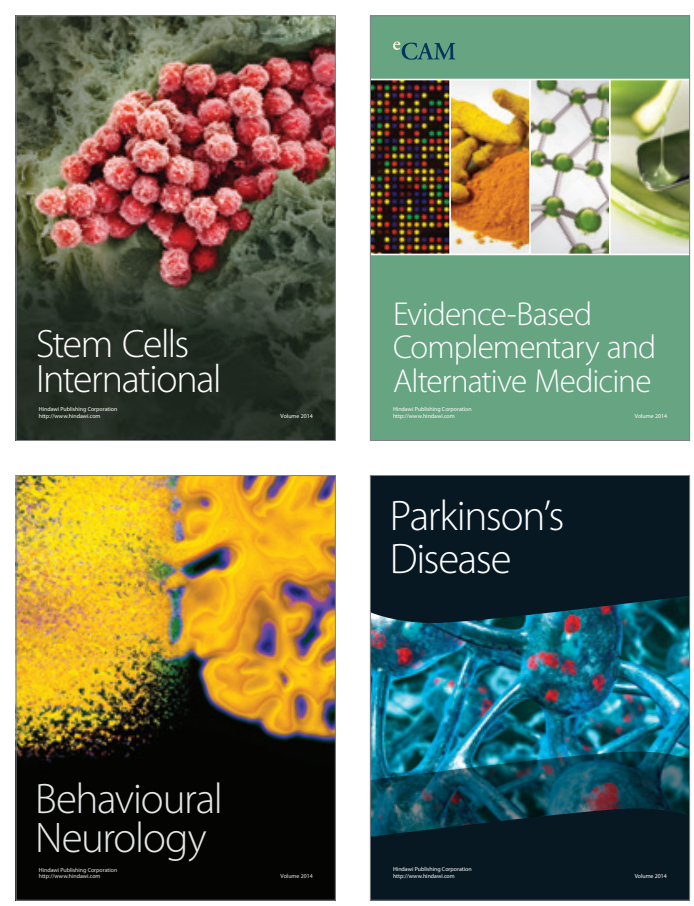

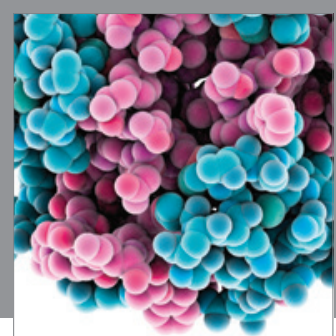

Journal of
Diabetes Research

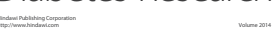

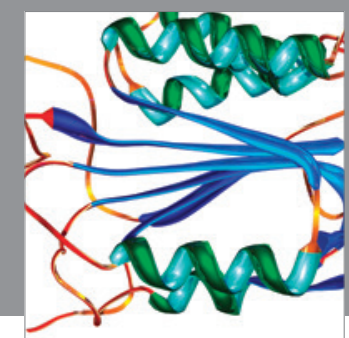

Disease Markers
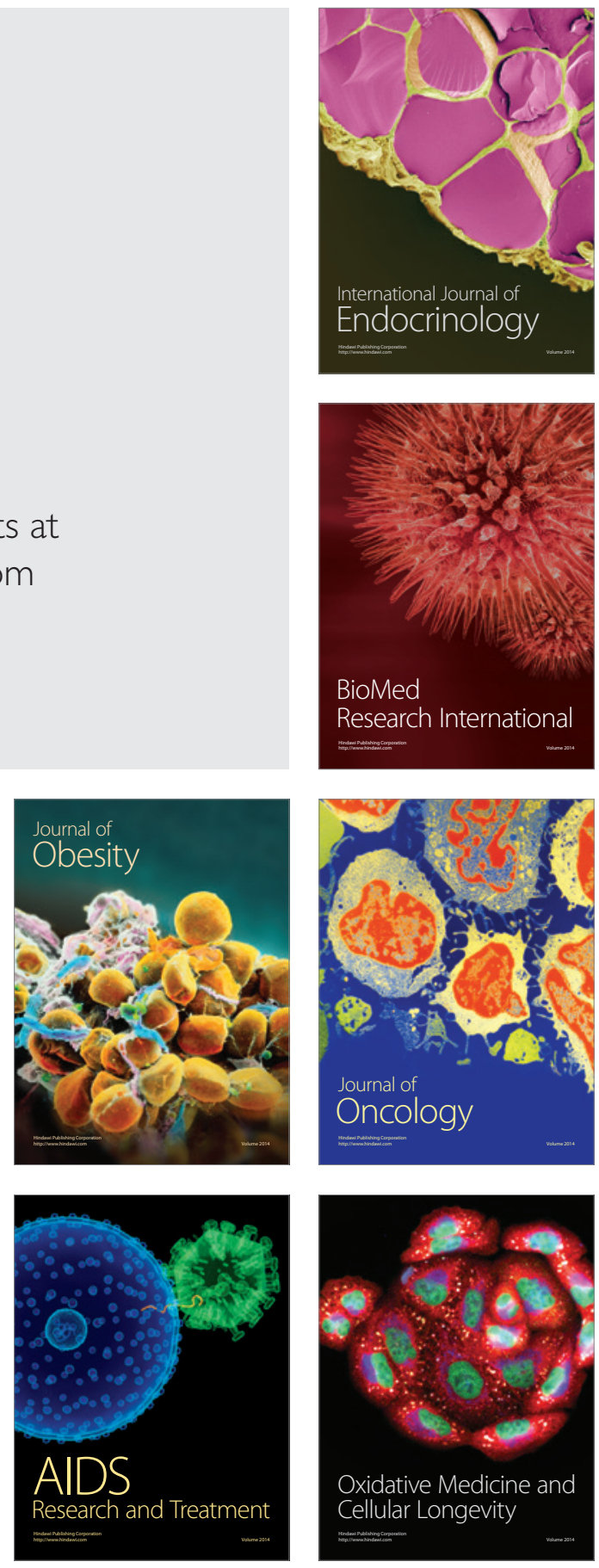